\title{
Recurrent and novel SS18-SSX fusion transcripts in synovial sarcoma: description of three new cases
}

\author{
Joanna Przybyl • Raf Sciot • Piotr Rutkowski • \\ Janusz A. Siedlecki • Vanessa Vanspauwen • \\ Ignace Samson • Maria Debiec-Rychter
}

Received: 22 May 2012 / Accepted: 9 August 2012 /Published online: 14 September 2012

(C) The Author(s) 2012. This article is published with open access at Springerlink.com

\begin{abstract}
Synovial sarcoma (SS) is an aggressive type of tumor, comprising approximately $10 \%$ of soft tissue sarcomas. Over $90 \%$ of SS cases are characterized by the $\mathrm{t}(\mathrm{X} ; 18)(\mathrm{p} 11.2 ; \mathrm{q} 11.2)$ translocation, which results mainly in the formation of oncogenic SS18-SSX1 or SS18-SSX2 fusions. In a typical $S S 18-S S X$ fusion transcript, exon 10 of $S S 18$ is fused to exon 6 of $S S X 1 / 2$. However, several variant fusion transcripts have been already described. In the
\end{abstract}

J. Przybyl $(\bowtie) \cdot J$. A. Siedlecki

Department of Molecular Biology, The Maria Sklodowska-Curie

Memorial Cancer Centre and Institute of Oncology,

5 W.K. Roentgen Street,

02-781, Warsaw, Poland

e-mail: joanna.przybyl@coi.pl

R. Sciot

Department of Pathology, K.U. Leuven and University Hospitals, Leuven, Belgium

P. Rutkowski

Department of Soft Tissue/Bone Sarcoma and Melanoma,

The Maria Sklodowska-Curie Memorial Cancer

Centre and Institute of Oncology,

Warsaw, Poland

J. Przybyl $\cdot$ V. Vanspauwen $\cdot$ M. Debiec-Rychter

Department of Human Genetics,

K.U. Leuven and University Hospitals,

Leuven, Belgium

I. Samson

Department of Orthopedic Surgery, University Hospitals,

Leuven, Belgium

J. Przybyl

Postgraduate School of Molecular Medicine,

Warsaw Medical University,

Warsaw, Poland present study, we examined the fusion transcript type in a series of 40 primary untreated SS tumor specimens using reverse transcription polymerase chain reaction and fluorescence in situ hybridization assay. We detected SS18SSX1 transcript in $22(55 \%)$ patients and SS18-SSX2 transcript in $17(42.5 \%)$ patients, while in one patient, none of $S S 18-S S X 1 / 2$ fusion transcripts were identified. Among the cases under study, two tumors carried novel SS18-SSX1 and SS18-SSX2 variant translocations that were allegedly created by an alternative splicing, and in additional case, an unusual translocation variant previously described by other group was found. Our data suggest that alternative splicing may play an important role in novel fusion transcript formation, and additionally we show that it may be a recurrent event in SS. Furthermore, we describe the first case of a complex rearrangement possibly linking SS to REPS2 gene.

Keywords Synovial sarcoma $\cdot$ Molecular markers $\cdot$ Fusion genes $\cdot$ SS18-SSX fusion genes

\section{Introduction}

Synovial sarcoma (SS) accounts for approximately $10 \%$ of soft tissue sarcomas. SS is an aggressive type of tumor which may arise in patients at any age but mainly develop in adolescents and young adults. SS originates principally in the extremities but may occur at any anatomic site. Metastases, which mainly affect the lungs, occur in approximately half of patients [1].

Cytogenetically, SS is characterized by the nonrandom presence of $\mathrm{t}(\mathrm{X} ; 18)(\mathrm{p} 11.2 ; \mathrm{q} 11.2)[2,3]$. This translocation is detected in more than $90 \%$ of SS cases and involves the 


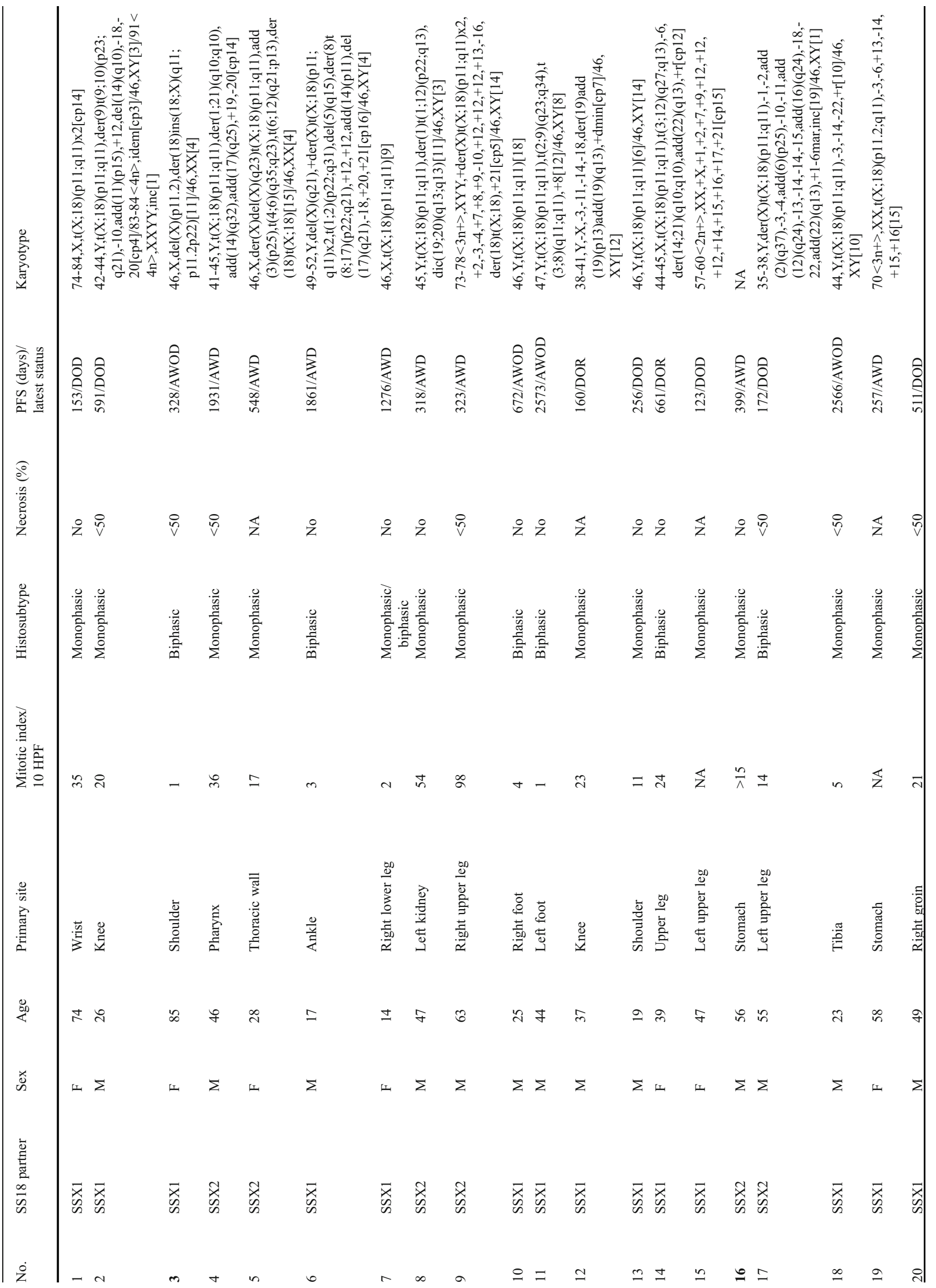




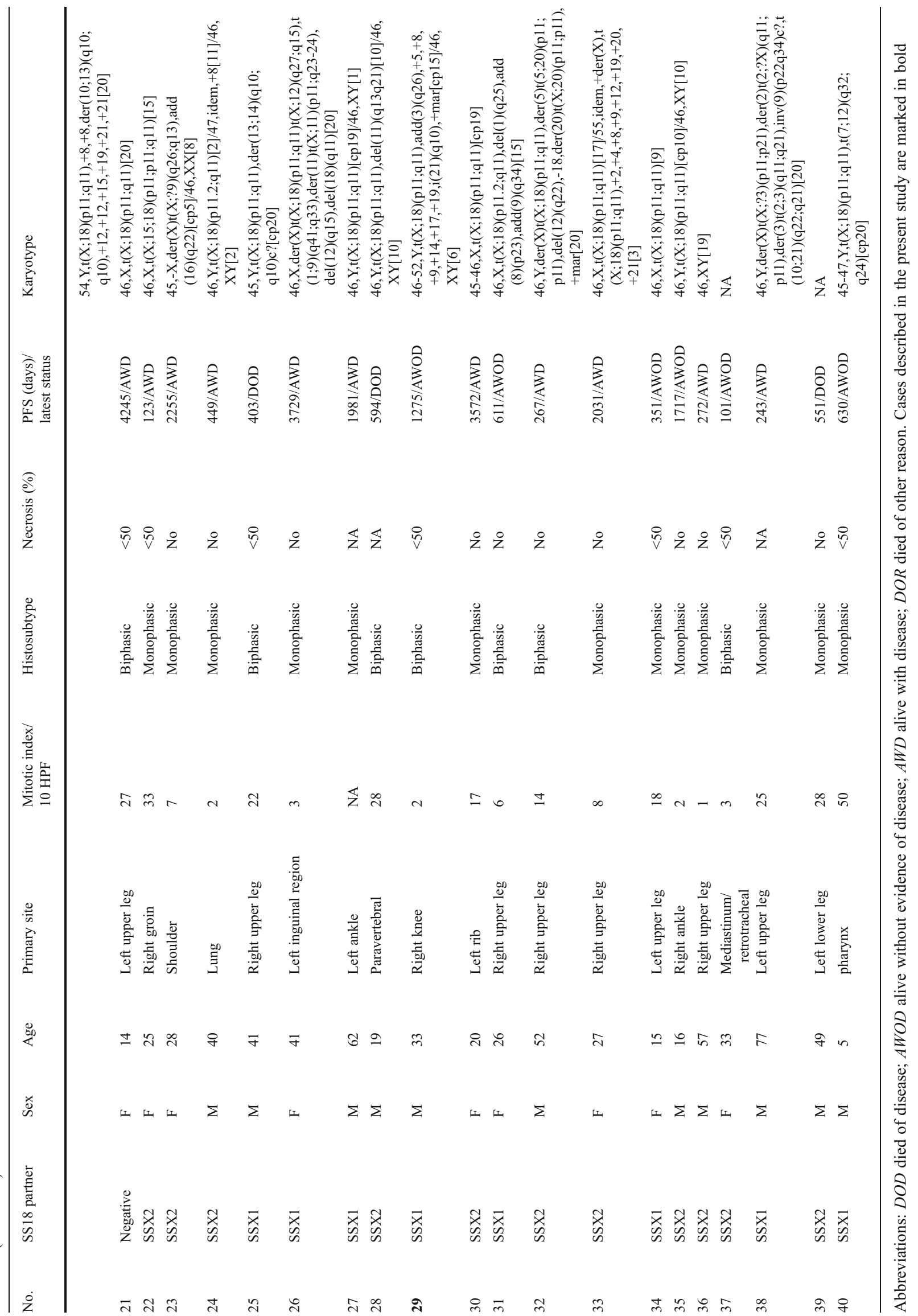


Table 2 Primers used for PCR and sequencing

\begin{tabular}{|c|c|c|c|c|}
\hline Designation & Sequence & Direction & Position & NCBI reference sequence \\
\hline SS18 & 5' AGGATATAGACCAACACAGCC 3' & Forward & $1242-1262$ & NM_001007559.1 \\
\hline SSX1 & 5' GGTGCAGTTGTTTCCCATCG 3' & Reverse & $493-512$ & NM_005635.2 \\
\hline $\mathrm{SSX} 2$ & 5' GGCACAGCTCTTTCCCATCA 3' & Reverse & $510-529$ & NM_175698.1 \\
\hline SSX4 & 5' GGCACAGCTGTTTCCCATCA 3' & Reverse & $460-479$ & NM_005636.3 \\
\hline
\end{tabular}

SS18 (previously known as SYT) gene on chromosome 18 and one of the $S S X$ genes on the X chromosome [4-6]. In a

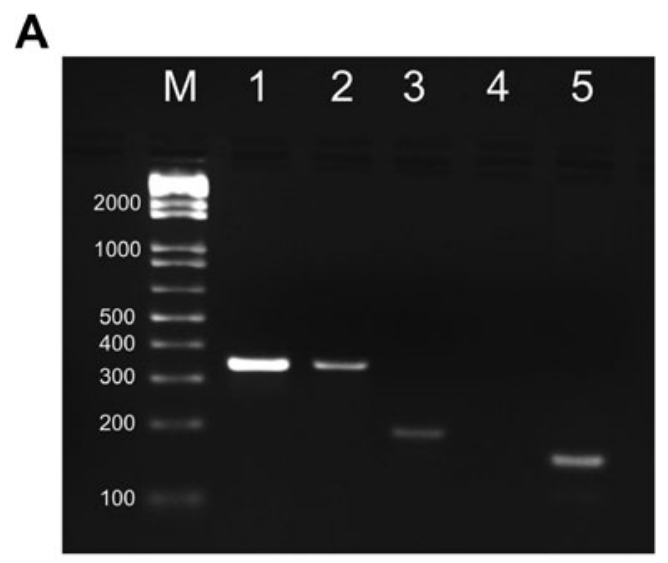

\section{B}

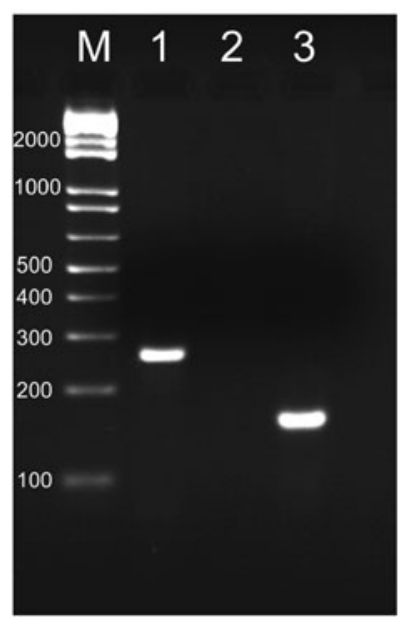

Fig. 1 Detection of novel fusion transcripts by electrophoresis in $2 \%$ agarose gel stained with ethidium bromide. a Detection of unusual SS18-SSX1 fusion transcripts. $M-1-\mathrm{kb}$ Plus DNA ladder (Invitrogen); 1-344-bp PCR product obtained from primary tumor specimen derived from patient \#3; 2-344-bp PCR product obtained from metastatic tumor specimen derived from patient \#3; 3-194-bp PCR product obtained from primary tumor specimen derived from patient \#29; 4-negative control, no cDNA added; 5-positive control, PCR product obtained from patient with the SS18-SSX1 fusion confirmed by sequencing. b Detection of novel SS18-SSX2 fusion transcript. $M-1$ kb Plus DNA ladder (Invitrogen); 1-263-bp PCR product obtained from primary tumor specimen derived from patient \#16;2-negative control, no cDNA added; 3-positive control, PCR product obtained from 1273/99 cell line with confirmed SS18-SSX2 fusion transcript typical SS18-SSX fusion transcript, exon 10 of $\operatorname{SS} 18$ is fused to exon 6 of $S S X 1 / 2$ [7]. Approximately two-thirds of tumors carry SS18-SSX1 translocation, and the SS18-SSX2 variant is found in one-third of cases [5, 8, 9]. Moreover, rare cases of SS18-SSX4 chimeric variants in SS have been described. However, SS18-SSX4 fusions have been characterized by high breakpoint variability, resulting in functional unpredictability [10-12]. The rare SS cases which lack the classical SS18-SSX fusion gene may represent tumors with unusual variant transcripts, which failed to be detected using conventional approaches [13]. Studies investigating the prognostic value of the different fusion types provide contradictory results. Several studies reported a more favorable outcome in patients carrying SS18-SSX2 fusions [5, 11, 14-17], and others failed to find any significant correlation between fusion type and clinical outcome $[9,18,19]$.

In the present study, we examined fusion transcript type using reverse transcription polymerase chain reaction (RT-PCR) in a series of 40 SS patients. We report two novel SS18-SSX1 and SS18-SSX2 variant translocations, and in one patient we detected unusual SS18SSX1 translocation variant previously described by other group [13].

\section{Materials and methods}

Patients

Forty fresh frozen surgical biopsies of primary tumors were obtained from the University Hospital Leuven, Belgium ( $n=$ 39) and the Maria Sklodowska-Curie Memorial Cancer Centre and Institute of Oncology, Warsaw, Poland $(n=1)$. The specimens originated from 24 males and 16 females with the mean age at the diagnosis of 38 years (range from 5 to 85 years). All tumors in our cohort were diagnosed as conventional synovial sarcomas by means of morphology and routine immunohistochemistry, with 26 tumors being classified as monophasic and 13 as biphasic. One specimen presented features of both mono- and biphasic histosubtypes. All specimens were collected with informed consent, according to the protocol approved by the local ethical committee. The clinicopathologic data of this series are shown in Table 1. 
Fig. 2 Identification of novel fusion transcript SS18-SSX1 involving REPS2 gene. a Schematic representation of the expected PCR product and novel SS18-SSX1 fusion transcript. The nucleotide positions derived from the original sequences of $S S 18$, SSX1, and REPS 2 mRNA are indicated in the upper part of the figure. b Nucleotide sequence of the 344-bp PCR product with predicted amino acid sequence of the chimeric protein
A

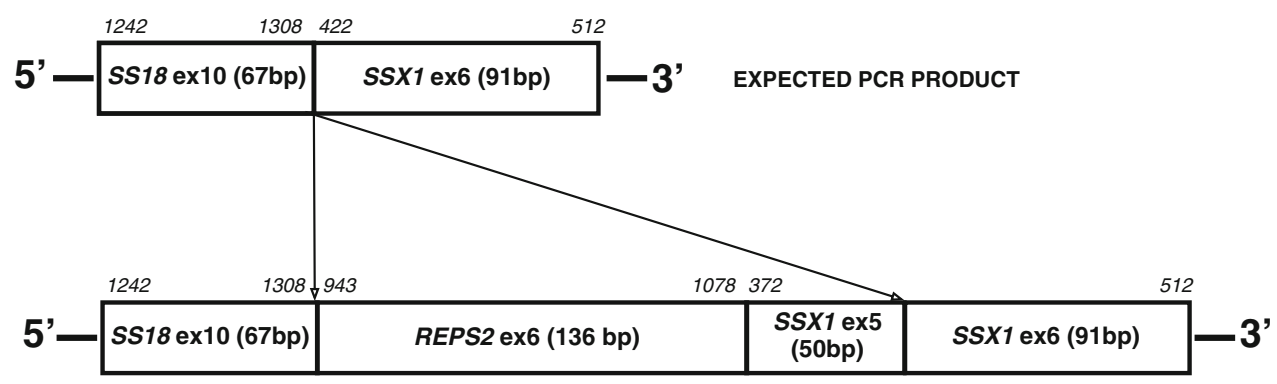

B

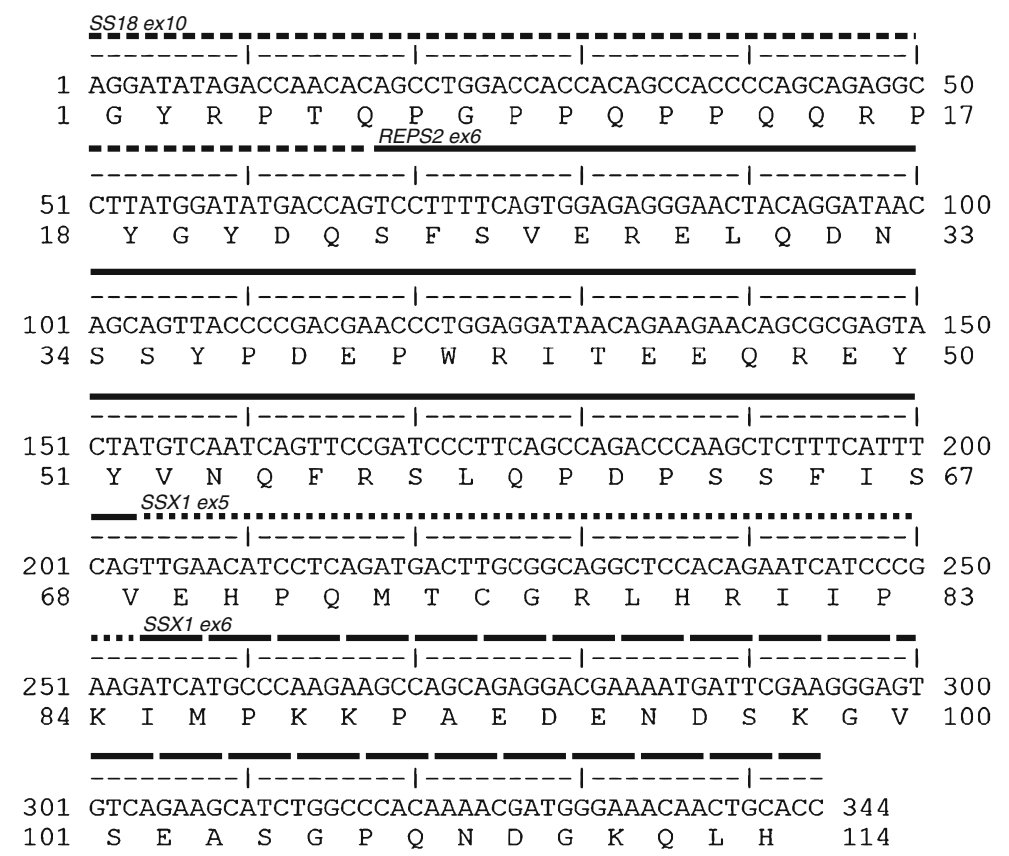

RNA extraction and reverse transcription

Total RNA was extracted from fresh frozen tumor specimens characterized as SS using miRNeasy kit according to the manufacturer's protocol (Qiagen). RNA quality was assessed using BIO-RAD Experion RNA StdSens Analysis system (BIO-RAD). One microgram of total RNA was reverse transcribed with oligo(dT) $)_{12-18}$ primers and random hexamers using SuperScript III Reverse Transcriptase (Invitrogen).

Fusion transcript detection by PCR

We performed SS18-SSX1 and SS18-SSX2 detection in all of examined cases, and additionally SS18-SSX4 detection in the case negative for $S S 18-S S X 1 / 2$ fusions. PCR was performed with two microliters of cDNA using AmpliTaq Gold DNA Polymerase (Invitrogen). Amplification was performed at $+94{ }^{\circ} \mathrm{C}$ for $30 \mathrm{~s},+58{ }^{\circ} \mathrm{C}$ for $60 \mathrm{~s}$, and $+72{ }^{\circ} \mathrm{C}$ for $60 \mathrm{~s}$ for 35 cycles, and the final extension was performed for $10 \mathrm{~min}$. Only the annealing temperature for SS18-SSX4 detection was $+57{ }^{\circ} \mathrm{C}$. Primers used for amplification are listed in Table 2 [20, 21]. cDNA from synovial sarcoma 1273/99 cell line (kindly provided by Professor Fredrik Mertens, Skone University Hospital, Lund University, Sweden) was used as a positive control of SS18-SSX2 amplification, and cDNA from patient with known SS18-SSX1, confirmed by direct sequencing, was used as a positive control of SS18-SSX1 amplification. Negative controls were also included in every step of the procedure. PCR products were analyzed by electrophoresis in $2 \%$ agarose gels stained with ethidium bromide and photographed.

Sequence analysis

PCR products were purified using QIAquick PCR Purification Kit (Qiagen). Direct sequencing of both strands of PCR products was performed using BigDye ${ }^{\circledR}$ Terminator v3.1 Cycle Sequencing Kit (Applied Biosystems) and analyzed on the 3130xL Genetic Analyzer (Applied Biosystems). Both strands of the PCR products were sequenced at least twice. Chromas 
A

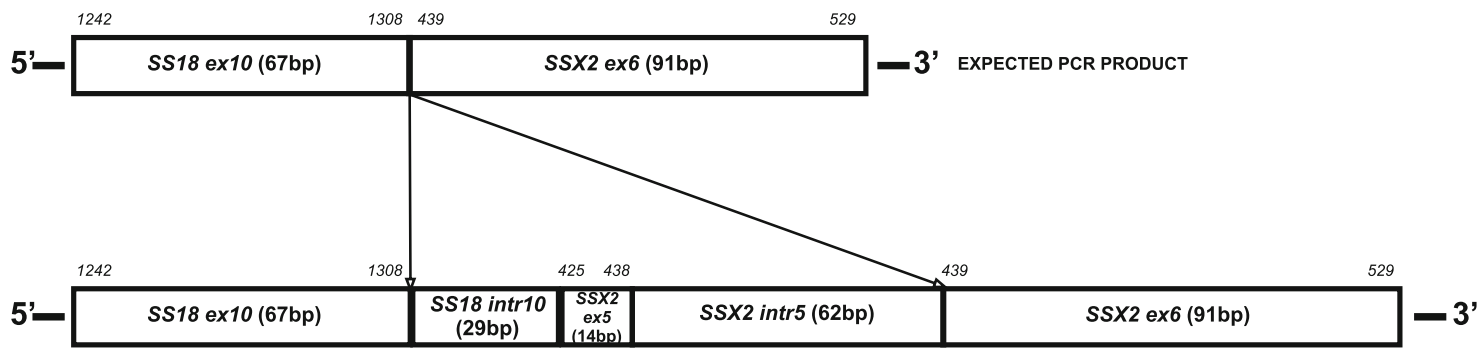

B

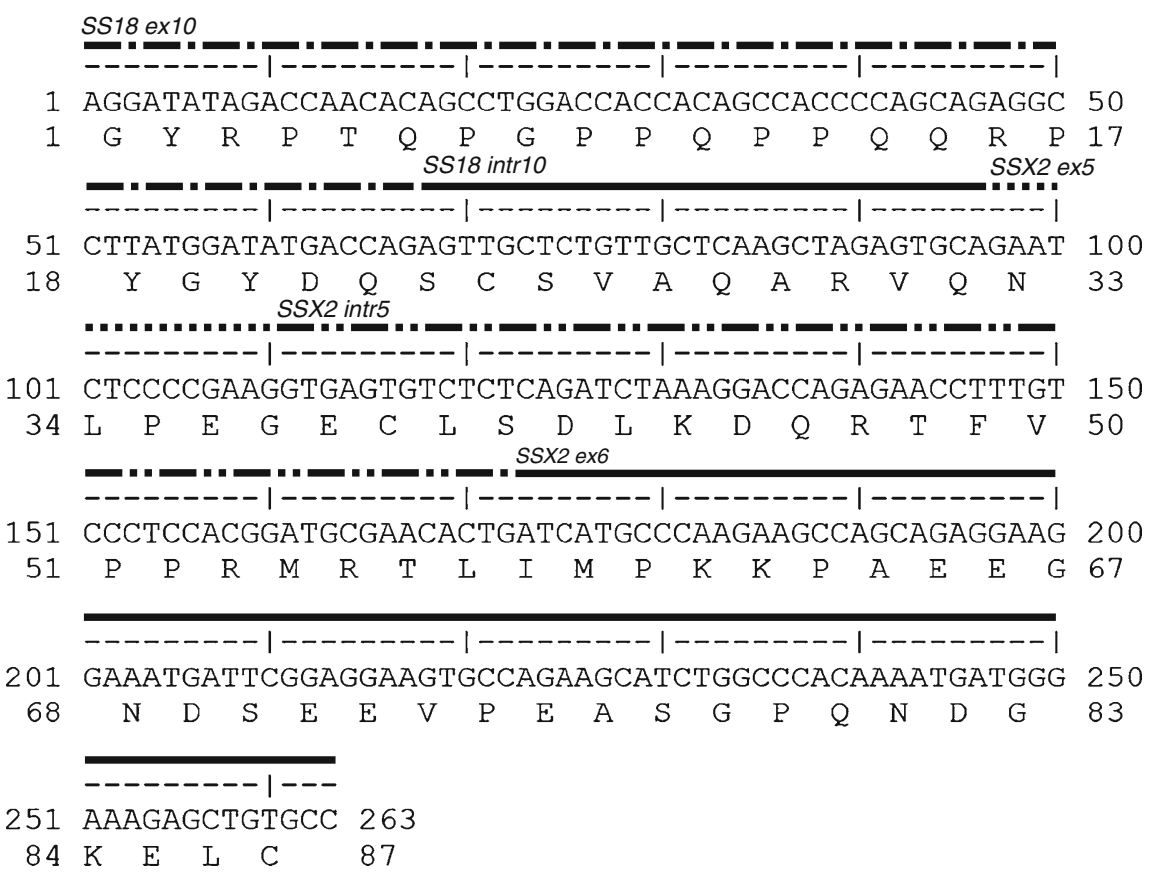

Fig. 3 Identification of novel fusion transcript SS18-SSX2. a Schematic representation of the expected PCR product and novel SS18-SSX2 fusion transcript. In the upper part of the picture, the nucleotide

Lite 2.01 software (Technelysium Pty Ltd) and BLAST software (http://blast.ncbi.nlm.nih.gov/Blast.cgi) were used for the computer analysis of obtained sequence data.

Fusion type detection by fluorescence in situ hybridization

Fluorescence in situ hybridization (FISH) assay was performed in selected cases to confirm the type of SS18-SSX1/2 translocations, according to the protocol described by Surace and coworkers [22].

\section{Results}

We detected SS18-SSX1 transcripts in 55\% $(n=22)$ and SS18SSX2 transcripts in $42.5 \%(n=17)$ of patients. In one tumor, we did not detect any fusion transcript using RT-PCR; positions derived from the original sequences of SS18 and SSX2 mRNA are indicated. b Nucleotide sequence of the 263-bp PCR product with predicted amino acid sequence of the chimeric protein

although FISH was not performed due to insufficient material, the karyotype of this specimen was available in the hospital database, revealing a $\mathrm{t}(\mathrm{X} ; 18)$. Among analyzed cases, we noticed larger than expected 158-bp PCR products in three patients (Fig. 1). These samples were subjected to sequence analysis. Obtained sequence data were aligned to reference fusion transcript sequences (SS18-SSX1-GenBank S79325, SS18-SSX2-GenBank S79332) and analyzed using the BLAST software. Two patients carried novel SS18-SSX variant translocations, and in one patient we detected atypical variant that was previously described by Amary et al. in 2007 [13].

SS18-SSX1 variant described by Amary et al. (2007)

An unexpected PCR product of $194 \mathrm{bp}$ was detected in SS of patient \#29. Direct sequencing indicated the identical SS18-SSX1 variant transcript that was previously described by Amary and 
coworkers [13]. This variant includes additional 12 codons derived from exon 5 of $S S X 1$, which results in the fusion of codon 410 of SS18 to codon 99 of SSX1 without reading frame shift. Amary et al. described this transcript variant in a 24-year-old male with a 30-mm tumor located in the right triceps. The tumor was classified as monophasic with $50 \%$ of necrosis and 19 mitotic figures per 10 high-power fields. Patient \#29 in our study was a 33-year-old male presenting biphasic a $30-\mathrm{mm}$ tumor in the right knee, with less than $50 \%$ of necrosis and two mitotic figures per 10 high-power fields. The patient underwent tumor resection directly after first diagnosis, and he was alive without disease 42 months after surgery.

\section{Novel SS18-SSX1 variant}

Tumor specimen \#3 was obtained from an 85-year-old female with a tumor of $105-\mathrm{mm}$ maximal diameter located in the shoulder. Additionally, a 30-mm metastatic tumor specimen from deep tissues of the shoulder was available from the same patient (metastasis developed 11 months after initial diagnosis). FISH analysis indicated $S S 18-S S X 1$ fusion transcript in both of these specimens.

PCR with primers specific for the SS18-SSX1 fusion transcript presented larger than expected products in both of the specimens. The nucleotide sequences of amplified products were identical. BLAST analysis showed an insertion of $186 \mathrm{bp}$ in the site of usual SS18-SSX1 junction. The additional nucleotides corresponded to $136 \mathrm{bp}$ of complete exon 6 of RALBP1 associated Eps domain containing 2 (REPS2) (NM_004726.2) and $50 \mathrm{bp}$ of complete exon 5 of $S S X 1$, indicating a complex rearrangement in this tumor (Fig. 2). REPS2-SSX1 insert was fused to the codon 410 of SS18 at the $5^{\prime}$ end and to the codon 111 of SSX1 at the 3' end. This rearrangement maintained the original reading frame. The predicted chimeric protein contains $410 \mathrm{~N}$-terminal codons of SS18, followed by 62 codons of REPS2-SSX1 fragment (codon 46 for valine situated at the junction site of these two genes) and $78 \mathrm{C}$-terminal codons of SSX1.

\section{Novel SS18-SSX2 variant}

We detected the third unusual fusion variant in a specimen \#16, derived from a 56-year-old male with a $80-\mathrm{mm}$ monophasic SS primary tumor located in the stomach. Patient underwent tumor resection directly after diagnosis. He developed metastasis after 13 months and was alive with disease after 42 months. FISH analysis indicated SS18$S S X 2$ fusion transcript in this specimen. PCR with primers specific for SS18-SSX2 amplified larger than expected product of $263 \mathrm{bp}$. The insertion of additional $105 \mathrm{bp}$ was fused in the position of usual SS18-SSX2 junction point. Codon 410 of $S S 18$ at the $5^{\prime}$ portion of fusion was followed by $29 \mathrm{bp}$ of intron 10 of $S S 18,14$ bp of exon 5 of $S S X 2,62 \mathrm{bp}$ of intron 5 of $S S X 2$, and 91 bp of exon 6 of $S S X 2$, which is usually present in the $3^{\prime}$ end of the fusion transcript (Fig. 3). This insertion conserved the original reading frame.

\section{Discussion}

The most common SS18-SSX fusion transcripts involve $410 \mathrm{~N}$-terminal codons of SS18 and $78 \mathrm{C}$-terminal codons

A

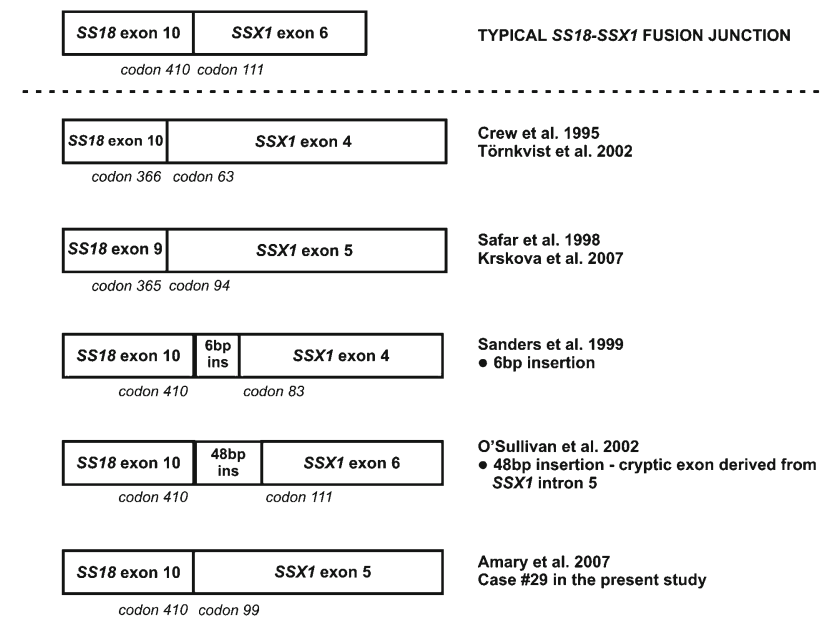

B

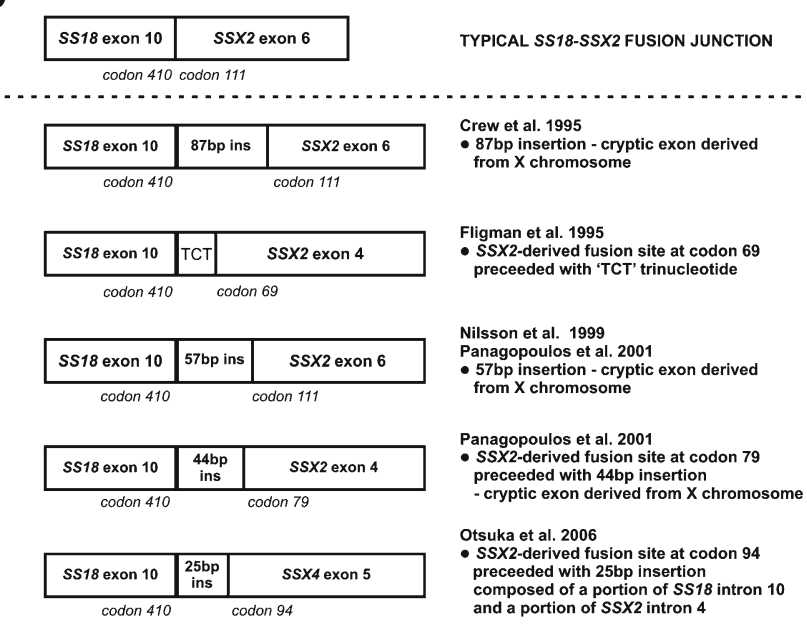

C

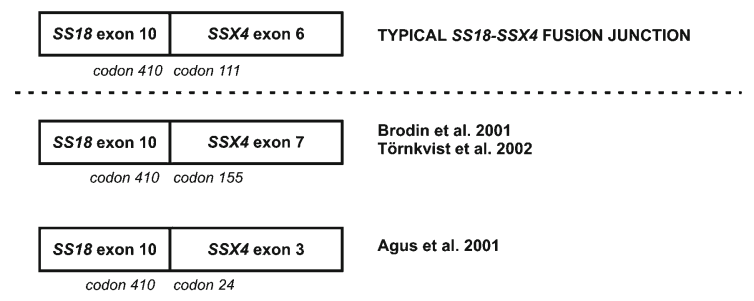

Fig. 4 Schematic representation of novel fusion sites in the unusual transcript variants of SS18-SSX1 (a), SS18-SSX2 (b), and SS18-SSX4 (c) described in the literature 
of either $S S X 1$ or $S S X 2$. To the best of our knowledge, there are 17 reports describing atypical variants of SS-associated translocations, which are mostly caused by small insertions [4, 7, 11-14, 23-32]. Novel SS18-SSX transcript variants are frequently created not only by the unusual junction of $S S 18$ and one of $S S X$ genes but also by the mutations within $S S 18$ or $S S X$ genes which occur apart from the fusion site, e.g., deletion or truncation of $S S X 1[26,32]$ or insertion in $S S 18$ sequence [12]. Figure 4 presents previously reported fusion variants characterized by different SS18-SSX junction sites. Our examination of fusion transcript type in a series of 40 SS primary tumor specimens revealed three unusual transcript variants, two of which were not published before.

The first unusual SS18-SSX1 transcript variant detected in our study was earlier described by Amary et al. [13]. Our detection of the identical fusion transcript variant confirms that the rare variants can be recurrent in SS patients and they are probably not caused by unique nor random events. Similar observations were already reported in several publications. Figure 4 indicates whether the atypical fusion variant was described in more than a single case.

The novel SS18-SSX1 transcript variant was detected both in primary and metastatic specimens derived from the same patient. This translocation involved another gene, i.e., REPS2, also known as $P O B 1$, located on the $\mathrm{X}$ chromosome at $\mathrm{Xp} 22$. The product of this gene is involved in the growth factor signaling and control of cell proliferation [33-36]. The expression of this gene might serve as a biomarker of favorable outcome in breast and prostate cancers; conversely, REPS 2 downregulation has been demonstrated in the progression of prostate cancer [34, 37-39]. The fusion site of REPS2 and $S S X 1$ involves amino acids encoded across a splice junctioncodon 303 for glycine on the border of exons 6 and 7 of REPS2 and codon 94 for valine at the junction of exons 4 and 5 of SSX1. Predicted chimeric protein sequence preserves valine in this position. Noteworthy, the junction between REPS2 and SSX1 was formed at the overlapping nucleotides "GGT" which are present at the 3 ' end portion of REPS2 and $5^{\prime}$ end portion of SSX1. Possibly, these overlapping nucleotides created a preferential site for the fusion of these genes. REPS2 exon 6, which is involved in this unusual fusion, encodes a portion of the Eps15 homology domain (residues 282-373). This domain has been described to interact with Epsin, Eps15, and p65 subunit of NFKB [37, 39]. However, gene expression profiles of synovial sarcoma cases described in the present study did not show any significant differences or correlations concerning REPS2 and its interactors (unpublished data). Therefore, the possible impact of REPS2 gene involvement in SS-associated translocation remains unclear. Apparently, this variant preserved the transforming function of the usual SS18-SSX1 fusion oncogene, which indicates that the mechanism of tumorigenesis in this case might have been similar as in other synovial sarcoma cases.
In addition, we have also detected novel SS18-SSX2 fusion transcript variant that consists of exonic and intronic regions of both $S S 18$ and SSX2 genes. This transcript was also presumably created by the alternative splicing mechanism since there are two cryptic "AG" acceptor sites and one cryptic "GT" donor site in the direct proximity of the fusion points. First, there is an AG signal immediately before the junction point of SS18 exon 10 and intron 10 in position 12615-12616 of original intron 10. Second, the cryptic acceptor splice site is present immediately before the fusion point of SS18 intron 10 and SSX2 exon 5, involving codons 104 and 105 of $S S X 2$ exon 5. Finally, directly after the $S S X 2$ intron 5 portion involved in the fusion, there is a cryptic donor splice signal GT, which was presumably used with the authentic acceptor splice site in the $3^{\prime}$ end of this intron, resulting in the junction of $S S X 2$ intron 5 and $S S X 2$ exon 6.

Cryptic splicing mechanisms have previously been reported in the unusual fusion transcript formation [28]. Our data confirm that alternative splicing may play an important role in novel fusion transcript formation and that it may be a recurrent event in SS.

In our series, $64 \%$ of the patients carrying SS18-SSX1 translocation and $71 \%$ of the patients with SS18-SSX2 fusion transcript developed local recurrence or metastasis. This finding supports previous reports $[9,18,19]$ showing no significant correlation between fusion type and clinical outcome.

Acknowledgments The project was conducted within the International PhD Projects Program (MPD) of the Foundation for Polish Science, and it was cofinanced by the European Union Regional Development Fund. This work was supported by the Polish Ministry of Science grant no. N N402 686640 and by a Concerted Action Grant 2010/16 from the K.U. Leuven.

Conflicts of interest None

Open Access This article is distributed under the terms of the Creative Commons Attribution License which permits any use, distribution, and reproduction in any medium, provided the original author(s) and the source are credited.

\section{References}

1. Sandberg AA, Bridge JA. Updates on the cytogenetics and molecular genetics of bone and soft tissue tumors: chondrosarcoma and other cartilaginous neoplasms. Cancer Genet Cytogenet. 2003;143 (1):1-31.

2. Limon J, Dal Cin P, Sandberg AA. Translocations involving the $X$ chromosome in solid tumors: presentation of two sarcomas with $t$ (X;18)(q13;p11). Cancer Genet Cytogenet. 1986;23(1):87-91.

3. Turc-Carel C, Dal Cin P, Limon J, Li F, Sandberg AA. Translocation X;18 in synovial sarcoma. Cancer Genet Cytogenet. 1986;23 (1):93. 
4. Panagopoulos I, Mertens F, Isaksson M, Limon J, Gustafson P, Skytting B, et al. Clinical impact of molecular and cytogenetic findings in synovial sarcoma. Genes Chromosomes Cancer. 2001;31(4):362-72.

5. Ladanyi M, Antonescu CR, Leung DH, Woodruff JM, Kawai A, Healey JH, et al. Impact of SYT-SSX fusion type on the clinical behavior of synovial sarcoma: a multi-institutional retrospective study of 243 patients. Cancer Res. 2002;62(1):135-40.

6. Mitelman F, Johansson B, Mertens F (eds) (2011) Mitelman database of chromosome aberrations in cancer. Available at: http:// cgap.nci.nih.gov/Chromosomes/Mitelman. Accessed on March 7, 2011.

7. Crew AJ, Clark J, Fisher C, Gill S, Grimer R, Chand A, et al. Fusion of SYT to two genes, SSX1 and SSX2, encoding proteins with homology to the Kruppel-associated box in human synovial sarcoma. EMBO J. 1995;14(10):2333-40.

8. Kawai A, Woodruff J, Healey JH, Brennan MF, Antonescu CR, Ladanyi M. SYT-SSX gene fusion as a determinant of morphology and prognosis in synovial sarcoma. N Engl J Med. 1998;338 (3): $153-60$.

9. Guillou L, Benhattar J, Bonichon F, Gallagher G, Terrier P, Stauffer E, et al. Histologic grade, but not SYT-SSX fusion type, is an important prognostic factor in patients with synovial sarcoma: a multicenter, retrospective analysis. J Clin Oncol. 2004;22 (20):4040-50

10. Skytting B, Nilsson G, Brodin B, Xie Y, Lundeberg J, Uhlén M, et al. A novel fusion gene, SYT-SSX4, in synovial sarcoma. J Natl Cancer Inst. 1999;91(11):974-5.

11. Agus V, Tamborini E, Mezzelani A, Pierotti MA, Pilotti S. Re: a novel fusion gene, SYT-SSX4, in synovial sarcoma. J Natl Cancer Inst. 2001;93(17):1347-9.

12. Brodin B, Haslam K, Yang K, Bartolazzi A, Xie Y, Starborg M, et al. Cloning and characterization of spliced fusion transcript variants of synovial sarcoma: SYT/SSX4, SYT/SSX4v, and SYT/ SSX2v. Possible regulatory role of the fusion gene product in wild type SYT expression. Gene. 2001;268(1-2):173-82.

13. Amary MF, Diss TC, Flanagan AM. Molecular characterization of a novel variant of a SYT-SSX1 fusion transcript in synovial sarcoma. Histopathology. 2007;51(4):559-61.

14. Nilsson G, Skytting B, Xie Y, Brodin B, Perfekt R, Mandahl N, et al. The SYT-SSX1 variant of synovial sarcoma is associated with a high rate of tumor cell proliferation and poor clinical outcome. Cancer Res. 1999;59(13):3180-4.

15. Inagaki H, Nagasaka T, Otsuka T, Sugiura E, Nakashima N, Eimoto T. Association of SYT-SSX fusion types with proliferative activity and prognosis in synovial sarcoma. Mod Pathol. 2000;13(5):482-8.

16. Sun Y, Sun B, Wang J, Cai W, Zhao X, Zhang S, et al. Prognostic implication of SYT-SSX fusion type and clinicopathological parameters for tumor-related death, recurrence, and metastasis in synovial sarcoma. Cancer Sci. 2009;100(6):1018-25.

17. Wei X, Sun Y, Zhao X, Cai W, Xia W, Lou D, et al. The influence of SYT-SSX fusion gene, E-cadherin and $\beta$-catenin on the metastasis of synovial sarcoma. Chin J Clin Oncol. 2010;37(4):205-8.

18. Ladanyi M. Correlates of SYT-SSX fusion type in synovial sarcoma: getting more complex but also more interesting? J Clin Oncol. 2005;23(15):3638-9. author reply 3639-40.

19. Takenaka S, Ueda T, Naka N, Araki N, Hashimoto N, Myoui A, et al. Prognostic implication of SYT-SSX fusion type in synovial sarcoma: a multi-institutional retrospective analysis in Japan. Oncol Rep. 2008;19(2):467-76.

20. Pelosi G. The Arkadi M. Rywlin International Pathology Slide Seminar Club, Seminar \#51, Case 14. Contributed by: Giuseppe Pelosi, MD, Division of Pathology and Laboratory Medicine, European Institute of Oncology and University of Milan School of Medicine, Milan, Italy. Available at: www.amr-seminar.org. Published on May 28, 2007. Accessed on February 7, 2012.

21. Mezzelani A, Mariani L, Tamborini E, Agus V, Riva C, Lo Vullo $\mathrm{S}$, et al. SYT-SSX fusion genes and prognosis in synovial sarcoma. Br J Cancer. 2001;85(10):1535-9.

22. Surace C, Panagopoulos I, Palsson E, Rocchi M, Mandahl N, Mertens F. A novel FISH assay for SS18-SSX fusion type in synovial sarcoma. Lab Invest. 2004;84(9):1185-92.

23. Fligman I, Lonardo F, Jhanwar SC, Gerald WL, Woodruff J, Ladanyi M. Molecular diagnosis of synovial sarcoma and characterization of a variant SYT-SSX2 fusion transcript. Am J Pathol. 1995;147(6):1592-9.

24. Safar A, Wickert R, Nelson M, Neff JR, Bridge JA. Characterization of a variant SYT-SSX1 synovial sarcoma fusion transcript. Diagn Mol Pathol. 1998;7(5):283-7.

25. Sanders ME, van de Rijn M, Barr FG. Detection of a variant SYTSSX1 fusion in a case of predominantly epithelioid synovial sarcoma. Mol Diagn. 1999;4(1):65-70.

26. Sonobe H, Takeuchi T, Liag SB, Taguchi T, Yuri K, Shimizu K, et al. A new human synovial sarcoma cell line, HS-SY-3, with a truncated form of hybrid SYT/SSX1 gene. Int J Cancer. 1999;82(3):459-64.

27. O'Sullivan MJ, Humphrey PA, Dehner LP, Pfeifer JD. t(X;18) reverse transcriptase-polymerase chain reaction demonstrating a variant transcript. J Mol Diagn. 2002;4(3):178-80.

28. Törnkvist M, Brodin B, Bartolazzi A, Larsson O. A novel type of SYT/SSX fusion: methodological and biological implications. Mod Pathol. 2002;15(6):679-85.

29. Storlazzi CT, Mertens F, Mandahl N, Gisselsson D, Isaksson M, Gustafson P, et al. A novel fusion gene, SS18L1/SSX1, in synovial sarcoma. Genes Chromosomes Cancer. 2003;37(2):195-200.

30. Otsuka $S$, Nishijo K, Nakayama T, Aoyama T, Ishibe $T$, Shibata $\mathrm{KR}$, et al. A variant of the SYT-SSX2 fusion gene in a case of synovial sarcoma. Cancer Genet Cytogenet. 2006;167(1):82-8.

31. Krsková L, Sumerauer D, Stejskalová E, Kodet R. A novel variant of SYT-SSX1 fusion gene in a case of spindle cell synovial sarcoma. Diagn Mol Pathol. 2007;16(3):179-83.

32. Dimitriadis E, Rontogianni D, Kyriazoglou A, Takou A, Frangia $\mathrm{K}$, Pandis N, et al. Novel SYT-SSX fusion transcript variants in synovial sarcoma. Cancer Genet Cytogenet. 2009;195(1):54-8.

33. Nakashima S, Morinaka K, Koyama S, Ikeda M, Kishida M, Okawa K, et al. Small G protein Ral and its downstream molecules regulate endocytosis of EGF and insulin receptors. EMBO J. 1999;18(13):3629-42.

34. Oosterhoff JK, Penninkhof F, Brinkmann AO, Anton Grootegoed $\mathrm{J}$, Blok LJ. REPS2/POB1 is downregulated during human prostate cancer progression and inhibits growth factor signalling in prostate cancer cells. Oncogene. 2003;22(19):2920-5.

35. Oosterhoff JK, Kühne LC, Grootegoed JA, Blok LJ. EGF signalling in prostate cancer cell lines is inhibited by a high expression level of the endocytosis protein REPS2. Int J Cancer. 2005;113 (4):561-7.

36. Tomassi L, Costantini A, Corallino S, Santonico E, Carducci M, Cesareni $\mathrm{G}$, et al. The central proline rich region of POB1/REPS2 plays a regulatory role in epidermal growth factor receptor endocytosis by binding to $14-3-3$ and $\mathrm{SH} 3$ domain-containing proteins. BMC Biochem. 2008;9:21.

37. Penninkhof F, Grootegoed JA, Blok LJ. Identification of REPS 2 as a putative modulator of NF-kappaB activity in prostate cancer cells. Oncogene. 2004;23(33):5607-15.

38. Doolan P, Clynes M, Kennedy S, Mehta JP, Germano S, Ehrhardt C, et al. TMEM25, REPS2 and Meis 1: favourable prognostic and predictive biomarkers for breast cancer. Tumour Biol. 2009;30(4):200-9.

39. Badway JA, Baleja JD. Reps2: a cellular signaling and molecular trafficking nexus. Int J Biochem Cell Biol. 2011;43(12):1660-3. 